\title{
From physical mobility to psychological mobilization: The benefits of changing location and caregiver in a mobile team for adolescent psychiatry
}

\author{
Sylvie Tordjman ${ }^{1,2}$ \\ ${ }^{1}$ Pôle Hospitalo-Universitaire de Psychiatrie de l'Enfant et de l'Adolescent (PHUPEA), CHGR et Université de Rennes 1, Rennes, \\ France; s.tordjman@yahoo.fr \\ ${ }^{2}$ Laboratoire Psychologie de la Perception, Université Paris Descartes, Paris, France
}

Received 25 April 2013; revised: 26 May 2013; accepted: 15 June 2013

Copyright (C) 2013 Sylvie Tordjman. This is an open access article distributed under the Creative Commons Attribution License, which permits unrestricted use, distribution, and reproduction in any medium, provided the original work is properly cited.

\section{ABSTRACT}

We have developed a mobile team for adolescents with psychological difficulties that can intervene within 48 hours, if necessary. Practically, caregivers working in pairs go wherever the adolescents are (home, General Practioner's office, etc.), travelling in a motorhome designed as a mobile office. This method allows us to approach more closely the adolescents and their families in the here and now that corresponds to our societal evolution. Most of the adolescents seen by the mobile team do not express any explicit demand but the demand is expressed by the professionals in direct contact with these adolescents in difficulty (school professionals, General Practitioners, etc.), who alert the mobile team and solicit the adolescents' parents to call the mobile team. One characteristic of this mobile team is the mobility of setting (by changing locations, including the use of a mobile office, and caregivers, so that multiple representations are mobilized). Statistical analyses conducted on 520 adolescents followed by the mobile team showed that the first meetings tend to take place in the family's home, subsequently transferring to the mobile office and finally in the community mental health centres. There is therefore a transition from the living space (a place that is part of the here and now) to the caregiving space (a space of thought and for thinking), with the mobile office serving as an intermediate step in this movement towards accessing care. Furthermore, there was a significant association between changes of locations and continuity of care. Thus, there were significantly more breakdowns in continuity when the consultations all take place in a single location (family home, mobile office, community centre). The results and their therapeutic implications will be discussed in this article, especially with regard to the key role played by physical movement in psychological mobilization, and by plurality of representations associated with different locations and caregivers.

Keywords: Mental Health; Adolescent; Mobile Team; Psychological Mobilization; Changing Locations; Changing Caregivers; Movement

\section{INTRODUCTION}

The use of mobile teams of caregivers represents an innovative approach to looking after troubled adolescents, even if mobility itself is nothing new. Social workers, youth workers and nurses have long carried out home visits, while child psychiatry and consultation-liaison psychiatry teams working in hospitals can also be said to be mobile.

These new mobile teams are intended to meet the needs of a society that has changed not only in the way it communicates and expresses its difficulties, but also in the very nature of those difficulties, which today includes parental separation (divorce now affects in France nearly half of all families), blended families, and issues of parental authority. Our child and adolescent psychiatric services increasingly find themselves providing family support and parental guidance, rather than long-term psychotherapy.

The geocentric mindset of previous generations has been replaced by an egocentric one, insofar as the members of today's society are no longer willing to come to 
us and instead wait for us to come to them. This societal trend began modestly enough, with the popularity of mail-order purchases, but swiftly gathered pace with the introduction of the Internet and the attendant explosion in sites offering everything from grocery deliveries to mobile hairdressing. As a public health service, we are certainly not exempt from these representations, and families now see themselves not as patients but as consumers. Conceptions of care have moved on ethically, as patients are now recognized as having rights, and there is a whole raft of legislation centred on respect for the individual and his or her rights. Our missions have changed, too, as priority is now given to prevention, and the principle of non-intrusion, whereby we wait for individuals to ask for help (something that often only happens once the situation has been allowed to deteriorate), has been abandoned in favour of a policy of literally going to the assistance of individuals in mental distress.

Reaching out to people does not mean doing things for them. Adolescents in difficulty naturally arouse a great deal of anxiety among frontline professionals (school professionals, General Practitioners, etc.), resulting in a relationship based on concern. This concern can easily translate into a desire to shoulder their burden for them, when instead we should be helping these adolescents to carry it themselves. This is in line with the distinction that Heidegger made between leaping-in solicitude and leaping-ahead solicitude. It is important to ensure that these adolescents take an active part in their treatment. Nor must we try to take their parents' place-indeed, one of the jobs of our mobile team is precisely to acknowledge the parents' skills and resources, and empower them by helping them rebuild their confidence. By finding innovative ways of adapting the therapeutic environment to meet the needs of the adolescents and their families (expectations, difficulties, biological rhythms, including waking and sleeping, mealtimes, etc.), rather than the other way round, where they have to bend to the constraints of the therapeutic environment, we turn them into active players who are directly involved in the treatment. This enhances the whole therapeutic process and, by so doing, heightens the satisfaction of professsionals and consumers alike. It also forces us to focus on and identify the needs of the adolescents and their families, and to treat them as people, rather than objects passively undergoing the health system.

Another feature of today's society is its virtual, if not physical, mobility-witness the exponential growth in mobile phone use, to the point where some families dispense with a landline altogether. It is thus incumbent upon us to adapt to this change and to show the adolescents and their families that we can be mobile, too, going to meet them wherever they happen to be (in their homes, but in other places, too). Whether we like it or not, we live in a society based on the immediacy of communication (telephone, fax, e-mail, etc.), in the here and now. This immediacy comes through both in the expression of needs and in the expected responses to these needs. It is certainly a feature of the families we work with, not least the adolescents, who are at a stage in their development where they are prone to impatience and impulsive acting out.

If we genuinely want to provide care that is tailored to our patients' needs, we must not attempt to swim against the tide. Instead, we must learn to react more rapidly, and use the modes of communication with which the adolescents and their families feel most comfortable, for there is no point making care more accessible if people are not allowed to express themselves in the only way they know how. This is probably one of the reasons why most international and national mobile teams in psychiatry try to intervene extremely rapidly, if necessary (no waiting lists), and also spend a great deal of their time talking with families (and indeed with other professionals) over the phone, as this allows them to set the therapeutic relationship in motion, or at the very least, establish the first tentative connections. Our mobile team adapts to what the family can do and listens to what it cannot do. Far from undermining the therapeutic process, this approach allows us to achieve that first, all-important encounter. We can then begin to move away from the immediate temporality, allowing patients to gain access to different forms of care that may include long-haul psychotherapy.

It was thus our awareness that society was operating in a new time-space that prompted us to set up a mobile team for adolescents with psychological difficulties that can intervene within 48 hours, if necessary. In practical terms, caregivers working in pairs go wherever the adolescents happen to be (home, school, or General Practitioners's office), travelling in a motorhome fitted out as a mobile office. This method allows us to get as close as possible to the adolescents and their families in the here and now. The professionals in direct contact with the adolescents in difficulty (school professionals, General Practitioners, etc.) are the ones who alert the mobile team and solicit the adolescents' parents to call the mobile team. Most of the adolescents seen by the mobile team do not show any explicit demand, either because they are not able to elaborate a demand of being helped, or because they do not know how and where to express it. Furthermore, asking for some help might be particularly difficult during adolescence because it could reinforce the fear of being dependent on others often observed in adolescents with difficulties. The objectives of the mobile team for adolescents with psychological difficulties, based on short-term interventions (5, 9 interventions on average and a maximum of 10 interventions) are focused on prevention or access to long-term therapy and care. 
In the following section, we focus on the two characteristic features of our mobile team, namely the mobility of setting (by changing the venue and locations, includeing through the use of a mobile office, and the caregivers, we mobilize representations, prevent patients from becoming fixated on a particular therapist or care structure, and make it easier for them to invest in any future follow-on treatment), and the mobility of process (the physical movement that allows us to intervene wherever the adolescent happens to be also brings about psychological movement).

\section{MOBILITY OF SETTING}

\subsection{Advantages of Using a Mobile Office and Changing Location}

Our mobile office provides a neutral and reassuring setting for our consultations (even if a place of consultation can never be entirely neutral). It also serves as a useful halfway house when we are called in by the school or the family, helping us to make a clear distinction between the place for caring and the place for learning or living. If, for example, the initial encounter takes place at the adolescent's school, we use the infirmary or an empty office-never a classroom-and all subsequent consultations take place outside the school premises. Similarly, our mobile office means that families can choose whether or not to let us into their homes and, more generally, can decide where the consultation is to take place. By offering them this freedom of choice (home, mobile office close to home or school, community mental health centre, etc.), we give families an active role to play from the very first phone call. They are actually less embarrassed than we thought they would be about allowing us into their homes, but the option of holding consultations in our mobile office parked nearby reassures the team members, who do not wish to feel they are intruding. We believe that the caregivers' perceptions are just as relevant as those of the families, insofar as the therapeutic relationship involves not just what the families feel but also what the team members feel. On occasion, meetings with families in their homes have been followed or preceded (depending on the situation) by one-to-one consultations with the adolescent in the mobile office parked next to his/her home.

We try to make the mobile office as attractive and un-office like for the troubled adolescents as possible (the motorhome contains a washroom, a waiting room, and an office seating up to seven people). We believe it is important to offer (and to use) a space for talking that adolescents are positive about, and which they can appropriate-a place they can cathect and which will allow us to connect.

In some situations, where the families and adolescents are embarrassed or unwilling to be seen in our company by their neighbours or peers, we park the motorhome a few minutes away on foot from the family home. It is, in any case, an unmarked vehicle, precisely to avoid their being stigmatised. The need to avoid being spotted by the neighbours is often driven by a fear of madness and shrinks, which is one of the reasons why people are loath to ask for help in the first place. In one extreme case, we even had to station our mobile office in a motorway car park an adolescent and his family drove past every day. Only in this halfway house, stranded in what was effecttively a no man's land, could they construct a space for thinking. The family members would troop out of their car, to be greeted by the two caregivers, disappear into the mobile office, emerge somewhat later, and drive away incognito. We sometimes wondered whether we would end up being taken for care dealers. Then there was the adolescent girl and her family who would only attend consultations if they took place in the mobile office parked right front of our community mental health centre, as though they could not quite bring themselves at that stage to go into the building. In other situations, in agreement with the adolescents and their families, we have found it more appropriate to travel in an unmarked car we have at our disposal. Repeated visits to their housing estates would make us conspicuous, and the adolescents' gangs would start identifying our motorhome as the loony van. Waiting for these adolescents to leave their estates and come to our centre would be equally out of the question.

Mobility therefore allows us to reach out to adolescents in the places that are most appropriate not just for them, but also for their families and their particular context. Interestingly, the venues chosen by the adolescents and their families change as time goes by, and the wide range of options allows us to discuss the next one with them at the end of each encounter. We believe that these changes of location are absolutely key to mobilizing them. They also help to move the treatment forward, as the adolescents and their families express themselves and talk about themselves differently according to the place and the professionals they encounter there. These variations in their narrativity help to mobilize their representtations, and open therefore news perspectives for their problem and their future.

Statistical analyses performed on 520 adolescents followed by the mobile team as part of our academic applied research show that the first meetings tend to take place in the families' homes, subsequently transferring to the mobile office and finally the community centre. There is therefore a transition from the place of living (a place that is part of the here and now) to the caregiving space (a space of thought and for thinking), with the mobile office serving as a crucial staging post in this move- 
ment towards accessing care. Furthermore, there is a significant association between changes of locations and continuity of care-not just that provided by our mobile team, but also any follow-on care. Thus, there are significantly more breakdowns in continuity when the consultations all take place in a single location, be it the family home, the mobile office, or the community centre. This finding underscores the key role played by physical movement in psychological mobilization, as well as by the plurality of representations associated with the different locations and caregivers. Furthermore, it has important therapeutic implications that go far beyond our own mobile team, overturning conventional therapeutic schemas and showing how place changes can make it easier for patients to move on to and stick with short- or longer-term follow-on treatment.

\subsection{Advantages of Changing Caregivers}

Changes in caregivers give families and adolescents an opportunity to show different sides of themselves to different professionals. This helps to mobilize the representtations not just of parents and adolescents, but also of team members. With each new meeting, we are able to replicate the richness of the very first interview or encounter, all the while maintaining a degree of continuity within the discontinuity, through the invariant presence of one of the two caregivers from the previous session (i.e., we move from Pair AB, to Pair BC, then to Pair CD, and so on). The family therefore retells its story each time, but can put a different slant on it, perhaps by introducing a new element. In other words, the scaffolding provided by previous encounters enables them to (re) work, mentalize and represent the problem to themselves in a different way. With the fresh caregiver comes a fresh perspective, especially since ours is a multidisciplinary team (there are 15 professionals in the mobile team including child and adolescent psychiatrists, psychologists, nurses, educators and social workers) and each player therefore has a slightly different approach, generating new questions for the family and new hypotheses for the team, which, in turn, bring out new aspects.

The key point here is that the repeated and systematic introduction of a new caregiver puts the mobile team in a position of not knowing. Unlike the classic doctor-patient situation, the demand for information flows the other way, in that it is the family that possesses the knowledge and we are the ones asking for it to be disclosed. The regular changeovers, meaning that none of the caregivers remain present from start to finish, create a situation where the family can appropriate its story, unwinding the thread that runs through the sessions, and play an active part both in unravelling the symptoms and in putting together the treatment plan. This, in itself, can be seen as the family becoming empowered and getting back into the saddle. On several occasions, much to our surprise, a change in caregiver has prompted the family to reveal a secret to the newly arrived caregiver that holds the key to the problem we are endeavouring to resolve. As for the mechanisms at work here, it may simply be that it is easier to talk to strangers about deeply personal matters. When troubled adolescents and their families see the same therapist for weeks, if not months or even years, they become trapped in a relational straitjacket and their representations become frozen, making it difficult, if not impossible, for them to express secrets that have never been spoken about and which provoke feelings of shame. In our experience, encountering a fresh therapist creates an element of surprise that destabilizes people and lowers their normal defences, allowing the unconscious to bubble to the surface and repressed experiences to be expressed through words. Our mobile team then devotes its remaining sessions to these newly disclosed secrets, in order to prevent them from generating any experiences of unworked-through irruption. This generally involves providing family support, centred on the emergence of this new demand, until a suitable long-term psychotherapy package can be put in place.

These changeovers are a source of reassurance for the mobile team, as they mean that all therapeutic avenues will be explored. They also mean that the referent of an adolescent/family/situation is neither a medical referent, nor a particular caregiver nor a designated psychotherapist, but instead the entire team.

A further consequence of these changeovers is that team members have to liaise with one another, meeting to discuss their progress at the end of each session in what becomes a transitional space of thought and for thinking. Allowing our young patients to see these relationships at work is an integral part of the therapeutic process, as they often have problems interacting either socially (e.g., repeated aggressive behavior), or with their family (e.g., attachment disorders), with the result that one of our jobs is to help them re-connect, or quite simply connect. By networking either with other members of the mobile team or with our external partners, we can help the adolescents to generate bonding representations. Put another way, by forging links between different teams, institutions or professionals, in the respect of their specific roles and identities, and showing that we can work together, all the while remaining different, we provide a template of how social ties can be represented and how individuals can be differentiated that resonates with their pathology. As such, it becomes a key component of the treatment, a means of enabling the adolescents to elaborate and form bonds. Moreover, this display of team dynamics revives the family's own dynamics, as though the family were mirroring the mobile team, and allows it to decentre itself more rapidly from the adolescent displaying the symptoms. 
One other, far from negligible benefit of changing caregivers is that while transference does occur, it is directed towards the entire team, rather than to any individual psychiatrist, psychotherapist or referent caregiver. This makes it easier all round-that is, for the mobile team, the family and the adolescent-to put a follow-on treatment package in place and bring our role to an end. The fact that our intervention will inevitably come to an end one day informs everything we do, and we broach the subject in the very first session, so that all the people involved, including the mobile team members, have time to represent the separation to themselves.

\section{MOBILITY OF THE PROCESS}

\subsection{From Physical Movement to Psychological Movement}

We can state the hypothesis that the physical movement implied by the notion of outreach and reinforced by our use of a mobile office elicits a psychological movement, mobilizing thought processes that were previously frozen.

Motion plays an important role in cognitive processes, whether we are moving under our own steam (walking, gesturing, performing physical movements) or availing ourselves of a mode of transport (train, car, ship), or simply find ourselves in a motion full environment, where it is the natural elements (wind or water), the objects or other people that are moving. These different situations are going now to be discussed.

Focusing first on the effects of physical motion, we have all had experiences where being in a moving car or train has stimulated our thought processes and the association of ideas. Physical motion overcomes mental inertia, and its speed affects the pace of our thinking, as illustrated by the American mathematician John Nash. This Nobel laureate, whose game theory has had major implications in economics, conceived and elaborated his theory while going on long walks. He has explained that it helped him to visualize numbers, put formulae together and organize his thoughts. One could almost say that this is how Nash's mathematical thought processes got into their stride. What is true for walking is equally true for moving bodies and for action in general. A number of recent studies of brain activity [1] suggest that the origin of thought lies partly- or even wholly- in motion, thus supporting Piagetian theory that thought is derived from action [2-4]. Other studies have drawn attention to the idea that the effect of movement on cognitive processes, particularly cognitive tuning, stems more from the purpose of that motion (e.g., approach or avoidance) rather than from the physical motion itself $[5,6]$. If, indeed, it is the purpose of our body movement that counts, then what about the effect of other people's motion on our mental activity? It opens important perspectives on the role of environment.

To better understand the effect of a moving environment on an individual's thought processes, such as a mobile team and a mobile office, it is necessary to consider that individual as a subject in interaction with his or her social and physical environment. If motion within our social and physical environment influences our cognitive processes, including the rhythm and speed of our thinking, a static environment where nothing is stirring can numb our thought mechanisms and provoke a "mental freezing”. Therefore, a movement forthcoming towards us from that environment might help us to escape from mental inertia and to initialize our thought processes. "We cannot begin to understand how the brain works", wrote Alain Berthoz, "if we fail to acknowledge that its main problem is bringing about motion in moments of inertia” [7].

The English neurologist Henry Charlton Bastian had recognized the importance of motion as early as 1880 , coining the term "kinaesthesia", or sense of movement [8]. This was described as a fully-fledged sense with the same status as the other five senses (Berthoz [7] referred to it as a sixth sense as recently as 2003), linking up the other senses and making them intelligible. It is motion that would "form the link" and allow for cognitive elaboration. It was in 1906 that Sherrington first referred to "proprioception". From then on, the notion of sense for proprioception was put to one side and motion ceased to be the subject of specific studies in psychology, except for Robert Woodworth in the United States and Henri Wallon in France. We are currently witnessing a revival of interest in this notion of "sense of movement", with Alain Berthoz (an engineer, psychologist and neuronphysiologist) and André Bullinger (a developmental psychologist) emphasizing the importance of motion. "For sensations to take on meaning, be perceived and become perceptions, there must be some kind of mental activity (Rousseau [9] also distinguished between sensation and perception, writing in Emile that 'our sensations are entirely passive, whereas all our perceptions or ideas spring from an active principle which judges'), the kind of mental activity that can organize these sensations by extracting their temporal and spatial regularities. These regularities include the characteristics of movement" [10]. Thus, regularities can consist of rhythms, such as the advance and retreat of waves on a beach, the rustling and fluttering of leaves in the breeze, or the course of the sun. The notion of rhythm, marked by discontinuity and the alternation of absence and presence, implies the notion of movement, However, as underlined by Berthoz [7], motion in its own right (i.e., independently of rhythm) is also a component of perception as regularities are. If regularities, with the search for invariants (identical pat- 
terns), play an important part in perception so, too, do irregularities, that is, the "variants" created by movement. Indeed movement creates "variants", i.e. changes that are a source of sensory stimulation (visual, tactile or auditory), triggering mental activity and “defrosting” frozen thought processes. One characteristic of these sensory stimulations arising from movement is that they are multimodal or cross-modal (leaves stirred by the wind and waves in the sea produce simultaneously visual and auditory stimuli), probably helping to ensure a more coherent perception of the environment.

Moreover, it is the variants arising from motion that allow us to partake in the dynamics of life. For example, internal physiological rhythms, such as the cycle of reproduction, generate repeated changes and movements (opposed to a frozen time) that are parts of the process of life. The four elements-earth, water, air and fire-are all endowed with motion, even if the Earth's rotational motion is imperceptible, and this motion is generally regarded as a symbol of life, energy and power. Indeed, motion allows us to generate energy. Interestingly, Aristotle's definition of motion (change), which is generally translated as "the actuality of a potentiality as such", was turned on its head by the French philosopher Théodore Bachelet [11] as "motion is potentiality that becomes actuality". We could also construe it as "the actuality of energy as such”, given that energy can turn into mental activity and subtends our thought processes. Changes brought about by motion can "energize" and mobilize static mental representations where time stands still, in complete contrast to the dynamics of life. It reminds us a Georgio Di Chiricho's painting where we can see a girl skipping rope in an empty landscape striking by its absence of movement coupled with the frozen motion of the young girl. To this frozen motion corresponds a suspended time, witness the unmoving hands of the clock painted on the tower. The whole painting exudes an oppressive and deathly atmosphere. It looks like we are waiting for a magic wand to restore the passage of time and restart the dynamic process of motion. In short, we are waiting for life to pick up where it has left off.

In addition, the notion of movement is closely bound up with the notion of space-time. As underlined by Bachelet [11] "All motion takes place in space; it determines space itself (...) All motion also takes place in time and constitutes a succession of it; it is through the divisions of movements that we mark the divisions of time. Not only is motion the sign and the measure of space and time, but it is also the link between these two ideas in our mind". We cannot mention the link between time and motion without returning once more to Aristotle. "It is also worth considering how time can be related to the soul; and why time is thought to be in everything, both in earth and in sea and in heaven. Is because it is an attri- bute, or state, or movement (since it is the number of movement) and all these things are movable (for they are all in place), and time and movement are together, both in respect of potentiality and in respect of actuality". Our interpretations of this relationship between movement and space-time, as well as of our own clinical observations, are supported by the effectiveness of outreach in situations of confinement, where adolescents have reached a point where they no longer feel able to leave the house. For by physically going to meet them, we are able to release their frozen psyche suspended in time and free them from their isolation in a continually shrinking space.

Finally, the theory of mirror neurons $[12,13]$ sheds an interesting light on the mechanisms that may be behind the therapeutic effects of the mobile team. We now know that the same brain structures are activated when we perform a movement as when we observe (or imagine) that movement being performed. This observed (or imagined) movement can be regarded as the inner simulation of the movement, inasmuch as there is no dissociation between perception and action, perception being simulated action [7]. For example, if a man is asked to walk a distance, then stand still and just imagine that movement, the duration of the mental journey is exactly the same as that of the physical journey, in a phenomenon known as isochrony [14]. If that individual is then asked to imagine himself making the same journey but carrying a load on his shoulders, the virtual load increases not just the duration of his mental journey, but also his heart rate and other indicators of the autonomic nervous system [15]. Imagining the journey therefore has the same consequences as actually making it. If we consider how this research might be relevant to the journeys made by our mobile team as part of our outreach scheme, we can hypothesize that observing this movement induces the same mobilizing effects in the adolescents as performing it does in the caregivers, as well as obviating the need for the adolescents to come to us.

\subsection{Reaching Out to the Adolescents and Their Families and Intervening Wherever They Happen to Be}

The mobile team's aim in reaching out to the other, that is, to the adolescents and their families, is to initiate a movement that may eventually translate into the adolescents reaching out to the other.

This outreach gives us the leverage we need to create an opening and allow the adolescents and their families to escape from the isolation in which they are often locked.

In our role as caregivers, we reach out to these adolescents in response to their distress and suffering. The message of this outreach is not, “you're asking for help, 
but you don't know it yet" (which would be thinking in their stead), but rather, "we're asking for help, as are all the people who are worried about you and who contacted us because you didn't seem well, and we can't just leave you like that". Another important message is that "we're coming to you because you're worth it and we won't give up on you, however great the difficulties". This soon gets through to the adolescents, and plays a vital mobilizing and renarcissizing function, as we often come across adolescents who have lost their self-esteem. Last but not least, this outreach sends an immediate signal that there is not one, but two protagonists asking for help, and allows us to work with the adolescents on how they relate to the other's request and, more generally on their acceptance of others.

Our mission of reaching out to those in mental distress, mobilizing them and helping them recognize that they need help can just as easily apply to teams of professsionals that have run into difficulty. Our mobile team, which we currently describe as a screening, caring and support team, can offer exactly the same help and support to the various players involved with adolescents (schools, general practitioners, paediatricians, the justice system, health and social welfare services). We are just as likely to come across a genuine or apparent refusal to ask for help from these teams as we are from troubled adolescents, either because these teams are too far gone to elaborate a request, or because they do not know how or where to express it. Informal contacts, whereby teams experiencing difficulty simply have to pick up the phone to seek help, are only possible if they actually know where to turn, have sufficient psychological resources and are available not just physically, but mentally, too. Our experiences have made us increasingly aware of the importance of thinking about and formalizing links and interfaces between institutions, establishing a flexible yet reassuring framework where people can find their bearings. By reaching out to partners and institutions in the education, justice and social welfare systems that are finding it a struggle to work with adolescents, we are able to mobilize them, just as we can adolescents and their families.

\section{CONCLUSIONS}

By placing our mobile team at the service of adolescents, we get to know more about their family and educational environment. Going into the families' homes has allowed us to identify situations of neglect and other factors that we would never have known about had they and their children attended consultations in one of our community mental health centres. Similarly, by going into schools, we have been able to pick up on distress or even depression among members of staff, and offer the appropriate support.
The mobility of our team also shows how intervenetions in the home can help to mobilize entire families. Our team is not the only one to derive benefit from working with family members, of course, as it is a feature of many other care approaches, notably those involving home visits. What sets our mobile team apart, however, is its ability to access all the family members, by supplementing encounters in the home with sessions in our mobile office parked nearby. All the members of our mobile team have received training in family therapy, and this has proved invaluable.

Wherever possible, we strive to involve and engage the whole family, in order to gain indirect access to the adolescent. Sometimes, our initial encounters in the families' homes take place in the absence of the adolescents, who shut themselves away in their rooms. Whenever this happens, we scrupulously respect their refusal to come out, in order to demonstrate that we fully recognize their freedom to make their own choices, and focus our attention on mobilizing their families. Each time we have found ourselves in this situation, the adolescent has subsequently agreed to meet us, probably owing to the new family dynamics we have created. It appears that by mobilizing the family, we are able to mobilize the young person. Some adolescents will not even allow themselves to accept and invest in their treatment unless we take care of their parents' needs first. We are usually able to overcome the adolescent's refusal to ask for help faster than one might expect-sometimes within just a couple of sessions. The most challenging situations arise when we are unsuccessful in mobilizing and engaging the family. The gift theory expounded by Marcel Mauss [16], sheds an interesting light on the family's pivotal role in mobilizing the adolescent, if we assume that an asker is someone who is in a position to receive, and that adolescents cannot be askers precisely because it is impossible for them to receive. Marcel Mauss [16] explains that a gift can be perceived as dangerous in institutional situations because "an accepted gift places its recipient in a position of obligation and gives its donor a hold over the beneficiary". This is especially relevant to the troubled adolescents we come across, who often have an intense fear of dependence on others. If it is the family that does the asking, then the adolescent can agree to take part in the encounters in order to reassure the worried family, and thus be in the position of giving. Several caregivers have described home visits where they have been able to persuade the adolescents to leave their rooms and join in the family discussion by asking them to come and help assuage their parents' concerns. Our mobile team's work with adolescents cannot, therefore, be dissociated from the work it carries out with families. By taking on the role of asker, the family supplies the rationale for the therapeutic alliance between the mobile team and the 
adolescent and his or her immediate or extended entourage. It is a virtuous circle, where the mobile team brings comfort to the family which, in exchange, supports its work.

Lastly, it is important to stress that the mobility of the setting and the process also contributes to the mobility of our project, keeping our ideas on the move in order to maintain a space for thought and for thinking. It allows our project, whose benefits and shortcomings are regularly discussed at meetings by the team, to remain a living, breathing project. When the mobile team was first set up, we made arrangements for its members to be supervised by a psychoanalyst (90 minutes every fortnight) so that they could work through their feelings and experiences. We believe these different spaces for thinking are absolutely vital, if we are to avoid falling into the trap of interventionism and mirroring the acting-out pathologies of the adolescents we see.

To conclude, we argue that the physical mobility of our team, with its mobile office and caregiver changeovers, elicits the psychological mobility not just of the troubled adolescents, but also of their families and the caregivers or teams who come into contact with them. By mobilizing their thought processes, and thus prompting them to ask for help, our team helps adolescents to regain a hold on reality by exposing them to multiple representations, making them aware of their relational intersubjectivity and above all instilling in them the idea that reality must be seen in the context of the past, the present and, perhaps above all, the potentialities of the future.

\section{ACKNOWLEDGEMENTS}

The mobile team was supported by the Centre Hospitalier Guillaume Regnier and the mobile office by a grant from la Fondation de France.

\section{REFERENCES}

[1] Becker, J. (2006) Relation of neurological findings on decoupling of brain activity from limb movement to Piagetian ideas on the origin of thought. Cognitive Development, 21, 194-198. doi:10.1016/j.cogdev.2005.11.002

[2] Piaget, J. (1952) The origins of intelligence in children. Norton (original work published 1936), New York. doi:10.1037/11494-000
[3] Piaget, J. (1954) The construction of reality in the child. Basic Books (original work published 1937), New York. doi:10.1037/11168-000

[4] Piaget, J. (1985) The equilibration of cognitive structures: The central problem of intellectual development. University of Chicago Press (original work published 1975), Chicago.

[5] Carmena, J.M., Carmena, M.A., Lebedev, M.A., Crist, R.E., O’Doherty, J.E., Santucci, D.M., Dimitrov, D.F., Patil, P.G., Henriquez, C.S. and Nicolelis, M.A. (2003) Learning to control a brain-machine interface for reaching and grasping by primates. Public Library of Science Biology, 1, 193-208.

[6] Raab, M. and Green, N. (2005) Motion as input: A functional explanation of movement effects on cognitive processes. Perceptual and Motor Skills, 100, 333-348. doi:10.2466/pms.100.2.333-348

[7] Berthoz, A. (2003) Le sens du mouvement. Odile Jacob, Paris.

[8] Jellinek, E.H. (2000) Dr. HC Bastian, scientific Jekyll and Hyde. The Lancet, 356, 2180-2183. doi:10.1016/S0140-6736(00)03508-X

[9] Rousseau, J.J. (1969) L’emile. NRF Gallimard, Paris.

[10] Bullinger, A. (1991) Le concept d'instrumentation: Son intérêt pour l'approche des différents déficits. In: Deleau, M., Ed., Collection Croissance de l'Enfant, Génèse de l'Homme, Presses Universitaires de France, Paris.

[11] Bachelet, T. (1876) Dictionnaire général des lettres, des beaux-arts et des sciences morales et politiques. Delagrave, Paris.

[12] Rizzolatti, G. and Arbib, M.A. (1998) Language within our grasp. Trends in Neurosciences, 21, 188-194. doi:10.1016/S0166-2236(98)01260-0

[13] Rizzolatti, G., Gartilucci, M., Camarda, R.M., Gallex, V., Luppino, G., Matelli, M. and Fogassi, L. (1990) Neurons related to reaching-grasping arm movements in the rostral part of area 6 (area 6a). Experimental Brain Research, 82, 337-350. doi:10.1007/BF00231253

[14] Decety, J., Jeannerod, M. and Prablanc, C. (1989) The timing of mentally represented actions. Behavioral Brain Research, 34, 35-42. doi:10.1016/S0166-4328(89)80088-9

[15] Decety, J., Jeannerod, M., Germain, M. and Pastène, J. (1991) Vegetative response during imagined movement is proportional to mental effort. Behavioral Brain Research, 24, 1-5. doi:10.1016/S0166-4328(05)80033-6

[16] Mauss, M. (2007) Essai sur le don. Presses Universitaires de France, Paris. 